Uludag Univ. J. Fac. Vet. Med.

33 (2014), 1,2: 57-61

\title{
Kanatlı Hayvanlarda Bağırsak Sağlığı ve Beslenme Arasındaki İlişki
}

\author{
Mukaddes Merve EFIL ${ }^{1}$ \\ Geliş Tarihi: 11.07.2014 \\ Kabul Tarihi: 16.10 .2014
}

\begin{abstract}
Özet: Bağırsak sağlığı; fizyoloji, mikrobiyoloji, immünoloji ve beslenme konularını kapsayan kompleks bir kavramdır. Kanatlı hayvanlarda bağırsak sağlığı ve beslenme arasında sıkı bir ilişki vardır. Bağırsak sağlığı bozulur ise; sindirim ve besin maddelerinin emilimi olumsuz yönde etkilenir. Bu durum büyüme performansını ve yemden yararlanmayı negatif yönde etkileyerek ekonomik kayıplara neden olur. Bu yüzden; kanatlı hayvanlarda bağırsak sağlığını etkileyen faktörler rasyonların formülasyonunda göz önünde bulundurulmalıdır. Bu derlemede; ekonomik bir kanatlı üretimi için önem taşıyan bağırsak sağlı̆̆ı ve beslenme arasındaki ilişkinin açıklanması amaçlanmıştır.
\end{abstract}

Anahtar Kelimeler: Kanatlı hayvanlar, beslenme, bağırsak sağlığı.

\section{The Relationship Between Gut Health and Nutrition in Poultry}

\begin{abstract}
Gut health is a very complex topic that comprises physiology, endocrinology, microbiology, immunology and nutrition. Gut health and nutrition in poultry are strictly interdependent. If gut health breaks down; digestion and nutrient absorption are negatively affected which can have a detrimental affect on growth performance and feed conversion efficiency leading to economic loss. Therefore, dietary factors affecting the gut health should be considered when formulating poultry diets. This article aims to explore the interrelation gut health and nutrition in poultry that is important for economical poultry production.
\end{abstract}

Key Words: Poultry, nutrition, gut health.

\section{Giriş}

Bağırsak sağlığı kompleks ve henüz tam olarak tanımlanamamış bir kavramdır. Bağırsak sağlığını oluşturan üç temel bileşenin; yem, bağırsak mukozası ve bağırsak mikroflorası olduğu ileri sürülmektedir. Yukarıda bahsi geçen bu faktörlerin her birisi; bağırsak ortamının hassas dengesinin korunmasında, bağırsak fonksiyonlarının düzenlenmesinde ve patojen mikroorganizmalara karşı oluşacak direncin artırılmasında etkilidir. Sağlıklı bir bağırsak ortamı ancak bu faktörler arasında oluşturulacak denge ile mümkün olmaktadır. Bağırsak sağlığg kav- ramının daha kolay anlaşılabilmesi için, gastrointestinal kanalın gelişimi ve bağırsak mikroflorası konularında bilgi sahibi olmak gerekmektedir.

\section{Gastro-İntestinal Kanalın Gelişimi}

Kuluçka dönemi süresince ince bağırsağın ağırlığındaki oransal artış, vücut ağırlığınınkine oranla daha fazladır. Kuluçka döneminin son 3 gününde, yani kuluçkanın 17. gününden yumurtadan çıkış gününe kadar; ince bağırsakların vücut ağırlığına oran1 \% 1'den \% 3.5'e yükselir $^{32}$. İnce bağırsakların ağırlıkça artışı 
yumurtadan çıkıș dönemi sonrasında da hızlı bir şekilde devam eder. Ayrıca yumurtadan çıkış dönemi sonrasında bağırsak gelişimi; enzimatik ve absorbtif aktivitelere bağlı olarak da artış gösterir $^{31}$. Yumurtadan yeni çıkan civcivlerin ince bağırsakları yaşamlarının ilk 2 haftası boyunca morfolojik, biyokimyasal ve moleküler değişimler geçirir. Ancak en önemli değişim ilk 24 saatte gerçekleşir. Civcivlerde ince bağırsakların gelişimi, neonatal dönemdeki memeliler ile benzerlik göstermektedir ${ }^{11}$. Civcivler yumurtadan çıktıktan sonra, sarı kesenin kalan kısmı karın boşluğuna çekilir. Kuluçka dönemi boyunca sarı kese civcivin beslenmesini sağlar ve çıkım sonrası gastro-intestinal kanalın yapısına katılır $^{20}$. İlk 48 saatte sarı kese ince bağırsakların gelişimine yardımcı olur. Bu süreçte civciv; sarı kese tarafindan sağlanan lipid formundaki enerji kullanımından, yem tarafindan sağlanan eksojen karbonhidratların kullanımına geçiş yapmak zorundadır ${ }^{20}$. Yemler, gastro-intestinal kanalın gelişimine katkı sağlar. Ancak yemin formu ve yemlemenin zamanlaması bağırsakların gelişiminde önemli bir rol oynar. Erken besleme yapılması bağırsak kanalının gelişimine katkı sağlamakta ve sarı kesenin ince bağırsağın yapısına katılmasina yardımc1 olmakta$\operatorname{dir}^{11,19,23,30}$. Erken beslemenin yanı sıra yumurta içi (in ovo) beslemenin de bağırsak gelişimi üzerine olumlu etkileri olduğu bildirilmektedir. $\mathrm{Bu}$ yöntem son 10 yıl içersinde uygulama alanı bulmuş ve çalışmalar halen Amerika ve İsrail'de patentli olarak sürdürülmektedir. Bu uygulama ile kuluçkanın 17. ve 18. günlerinde eksojen besin maddelerinin amniotik siviya verilmesi; bağırsak kapasitesini ve villusların sayısını artırarak bağırsak gelişimini hızlandırmakta, ayrıca karbonhidrat sindirimini de olumlu yönde etkilemektedir. Bilimsel çalışmalar, in ovo beslenen civcivlerin ince bağırsaklarının fonksiyonel açıdan konvensiyonel olarak beslenen 2 günlük yaştaki civcivlerin bağırsaklarıyla eş değer olduğunu ve bu civcivlerin kontrol grubundakilere göre daha yüksek canlı ağırlığa sahip oldukları$\mathrm{n} 1$ göstermiştir ${ }^{28}$. Hindiler üzerinde yapılmış bir çalışmada ise; amnion içerisine arjinin ve beta hidrosi beta metil bütirat enjekte edilmesinin konvansiyonel olarak yetiştirilen hindilere göre daha yüksek sindirim ve emilim kapasitesi sağladığı gösterilmiştir ${ }^{9}$. Kanatlı hayvanlarda yemlemenin erken yapılmaması, bağırsak gelişimini azaltmakta ve performansı düşürmektedir ${ }^{3,11,23}$. Genellikle yumurtadan çıkım ile civcivlerin kümese yerleştirilmeleri arasında geçen ortalama 24-72 saatlik süre zarfinda yemlemenin yapılamaması, bağırsak fonksiyonlarında ve verim özelliklerinde düşmeye neden olmakta ve yaşamın ilerleyen dönemlerinde bu olumsuz etkinin üstesinden gelinememektedir ${ }^{11,30}$.

\section{Bağırsak Mikroflorası}

Gastro-intestinal kanalın mikroflorasını; bakteri, fungi ve protozoalar oluşturmakla birlikte, bakteriler florada daha baskın olarak bulunmaktadır ${ }^{10}$. Farklı bakteri türlerinin farklı özellikleri (farklı substrat ve büyüme gereksinimleri, sindirim ürünlerinin kimyasal bileşimleri gibi) gastro-intestinal mikrofloranın kompozisyonunu belirlemektedir ${ }^{1}$. Misır, sorgum, arpa, yulaf veya çavdar içeren rasyonlarlar ile beslenen broylerlerde farklı etkiler gözlemlenmiştir. Misır ve sorgum ağırlıklı rasyonlarla beslenenlerde gastro-intestinal kanalda Enterococcus artarken, arpa ağıllıklı. rasyonlarla beslenenlerde Laktobasillus, yulaf ağırlıklı rasyonlarda Escherichia ve Laktococcus, çavdar ağırlıklı rasyonlarla besleme sonucunda ise Streptococcus artış göstermiştir ${ }^{1}$. Gastro-intestinal kanalın farklı bölümlerindeki bakteri popülasyonları da farklılık göstermektedir ve proksimal kısımlarda popülasyon yoğunluğu artma eğilimindedir ${ }^{24}$. Her bölge kendine özgü tek bir mikrobiyel profili geliştirir ve yaş ile birlikte bu mikrobiyel topluluk çok daha kompleks hale gelir ${ }^{18}$.

Yumurtadan çıkıştan sonraki ilk saatler, gastro-intestinal mikrofloranın oluşumu için kritik bir süreçtir. Kuluçkadan çıkan civcivlerin sindirim kanalı steril olup patojen mikroorganizmaların kolonizasyonuna aşırı derecede duyarlıdır. Çıkımı takiben maternal, çevresel ve yem kaynaklı çok sayıda mikroorganizma hızlı bir şekilde sindirim kanalına yerleşir ve gastrointestinal mikroflora yaşla beraber stabil bir hale gelir $^{24}$. Konuya ilişkin çalışmalar, mikrofloranın yaş, rasyon, ırk ve coğrafi özellikler ile değişebileceğini göstermiştir ${ }^{18}$. Apajalahti ve ark. ${ }^{2}$ tarafindan broyler civcivler üzerinde yapılan bir çalışmada, çıkımdan 1 gün sonra ileum ve sekum içeriğinin her bir gramındaki bakteri yoğunluğunun $10^{8}$ ile $10^{10}$ arasında değişiklik gösterdiği saptanmıştır. İlk 3 gün içinde ileumdaki bakteri sayısının her bir gram içerikte $10^{9}$, a ulaştığı, sekum için bu rakamın $10^{11}$ düzeyinde olduğu ve takip eden 30 gün için bu rakamların stabil düzeyde kaldığı bildirilmiştir. Henüz stabil bir mikrofloraya sahip olmayan civcivlerde erken zamanda oluşturulacak koruyucu mikrofloranın patojen mikroorganizmalar üzerine etkisi "rekabetçi dışlama" (Competitive Exclusion) 
veya "Nurmi Kavramı" olarak tanımlanmıştır. Bu kavram; sağlıklı yetişkin kanatlılardan elde edilen bağırsak mikroflorasının, yumurtadan yeni çıkmış civcivlere çeşitli yollarla uygulanmas1 ve patojenlerin kontrol altında tutulmasi olarak açıklanmaktadır ${ }^{21}$. Bilindiği gibi gastrointestinal kanaldaki mikroorganizmalar yararlı ve patojen mikroorganizmalar olarak iki gruba ayrilır. Patojen mikroorganizmalar; lokalize ya da sistemik enfeksiyonlardan, intestinal pütrifikasyonlardan ve toksin üretiminden sorumludur. Yararlı mikroorganizmalar ise vitamin üretimi, immun sistemin nonpatojenik mekanizmalarla uyarılması ve zararlı mikroorganizmaların inhibisyonu gibi faydalı etkilere sahiptir ${ }^{15}$. Daha önce de vurgulandıği gibi, gastro-intestinal mikrofloranın profili özellikle rasyondan etkilenmekte ve rasyondaki değişimler mikrofloranın profilini değiştirmektedir. Rasyon kompozisyonu ve mikroflora arasındaki etkileşim; intestinal gelişimi, mukozal yapının oluşumunu ve mukus kompozisyonunu önemli düzeyde etkilemektedir ${ }^{1}$.

\section{Bağırsak Sağlığını Etkileyen Faktörler}

Kanatlı hayvanlar tarafindan sindirilen yem; besin maddelerini, besin maddesi niteliğinde olmayan maddeleri, yararlı ya da zararlı mikroorganizmaları içerebilmektedir. Başka bir ifadeyle gastro-intestinal kanal, kanatlının patojenlere maruz kalan başlıca vücut bölümlerinden birisidir. Gastro-intestinal kanal, seçici geçirgen özelliği ile besin maddelerinin vücuda emilimini sağlarken, rasyondan kaynaklanan zararlı maddelerin vücuda geçişini önlemekte$\operatorname{dir}^{16}$.

Kanatlı hayvanlarda rasyona yönelik birçok faktör, enfeksiyöz hastalık ajanları, çevre ve yönetim uygulamaları; bağırsak sağlığını negatif yönde etkileyebilmekte ve bunun sonucunda da performans ve yemden yararlanma gibi üretim parametreleri olumsuz yönde etkilenmektedir. Aşağıda kanatlı hayvanlarda bağırsak sağlığını etkileyen faktörler sırası ile ele alınmıştır.

\section{Rasyon}

Nişasta yapısında olmayan polisakkaritler (NYOP)

Rasyon bileşimine giren yem hammaddeleri, bunların oranı ve uygulanan teknolojik işlemler bağırsak sağlığg ile yakından ilişkilidir. Bağırsak mikroflorası ve histomorfolojisi, ras- yonda kullanılan tahıl tipine, içerdiği NYOP'lerin oranına ve kimyasal yapısına bağlı olarak kolaylıkla değişebilir. Yapılan çalışmalarda yüksek miktarda NYOP'leri içeren rasyonların; bağırsak mikroflorasındaki bakteri popülasyonunda köklü değişikliklere neden olarak, yemlerin geçiş süresini ve sindirimini olumsuz yönde etkilediği gözlemlenmiştir. Kanatlı rasyonlarında kullanılan tahılların tümü değişik düzeylerde beta glukan ve arabinoksilanlar gibi NYOP'leri içermektedir ${ }^{14}$. NYOP'lerin düzeyi arpa, buğday, yulaf ve çavdar da oldukça yüksektir. Bu maddeler, kanatl-nin sindirim sisteminden salgilanan enzimlere karşı dayanıklıdır ve bağırsak lümeninde viskoz bir içerik oluşmasına neden olarak, dışkının yapışkan bir nitelik kazanmasına yol açarlar ${ }^{5}$. Bağırsak içeriğinin viskozitesindeki artış ise sindirim ve sağlik problemlerinin oluşumuna neden olarak, kanatlı performansının azalmasına yol açar. Kanatlı rasyonlarına spesifik eksojen enzimlerin ilave edilmesiyle NYOP'lerin yol açtığı bu olumsuz etkilerin üstesinden gelinebi$\operatorname{lir}^{17}$.

\section{Yemlerin fiziksel yapısı ve formu}

$\mathrm{Bu}$ konuda yayımlanmış çalışmalardan farklı sonuçlar elde edilmiş olsa da, yemlerin fiziksel formları intestinal kanalın morfolojik ve fizyolojik özeliklerini etkilemektedir ${ }^{8}$. İnce öğütülmüş yemler, kaba ögütülmüş yemlere nazaran nekrotik enteritis ile ilişkili mortalite oranlarını artırabilmektedir. Branton ve ark. ${ }^{4}$ çekiçli değirmende öğütülmüş buğdayın (ince ögütülmüş) broylerlerde mortalite oranını \% 28.9'a yükselttiğini, kaba ögütülmüş buğdayda ise mortalite oranının \% 18.1 düzeyinde kaldığını gözlemlemişlerdir. Araştırmacılar, mortalitelerin nekrotik enteritis ve koksidiyozun kombine etkileri sonucunda şekillendiğini bildirmişlerdir.

Broyler rasyonlarında bütün buğday (öğütülmemiş) kullanılmasının, gastro-intestinal kanalın özellikle de taşlığın gelişimini sağlayarak bağırsak sağlığına katkıda bulunduğu saptanmıştır ${ }^{8}$. Ayrıca, broyler beslemede bütün buğday kullanılmasının intestinal kanalda Salmonella Typhimurium ve Clostridium perfringens sayılarında azalmaya yol açtığ 1 bildirilmiştir ${ }^{8}$. Bazı çalışmalarda kanatlı rasyonlarında bütün buğdayın kullanılması yemden yararlanmayı iyileştirirken ${ }^{22}$, bazılarında ise bu parametre üzerinde herhangi bir pozitif etki saptanmamıştır. Svihus ve ark. ${ }^{27}$ bütün buğday içeren rasyonların canlı ağırlık ve yemden yararlanma üzerine önemli bir etkisinin olmadığını ancak bu 
rasyonların içerdiği besin maddelerinin öğütülmüş buğday içeren rasyonlar ile karşılaştırıldığında daha etkin bir şekilde sindirilip absorbe olduğunu bildirmişlerdir. Besin maddelerinin sindirim ve emiliminde gözlenen bu iyileşmenin, artan pankreas ve karaciğer salgılarından kaynaklanabileceği ileri sürülmüştür.

\section{Enfeksiyöz Ajanlar}

Bakteri, virüs ve diğer enfeksiyöz ajanlar ile non-enfeksiyöz ajanlar çeşitli enterik hastalıklara yol açarak bağırsak sağlığını olumsuz yönde etkilerler. İntestinal kanalda bakteriler tarafından oluşturulan hafif şiddetteki enfeksiyonlar yemden yararlanma oranını düşürürken, şiddetli enfeksiyonlar yüksek mortalite ile sonuçlanabilir. Bu duruma Clostridium perfringens tarafından oluşturulan nekrotik enteritis örnek olarak gösterilebilir. Clostridium perfringens; damızlık çiftlikleri, kuluçkahaneleri, yetiştirici kümesleri ve bitkileri kontamine edebilmektedir ${ }^{6}$. Nekrotik enteritiste oluşan lezyonlar, bağırsaklarda hasar meydana getiren diğer bakteriyel enfeksiyonların yol açtığı lezyonlar arasında en şiddetli olanlar arasındadır. Bu lezyonlardan bakteri tarafindan oluşturulan toksinler sorumlu tutulmaktadır. Bağırsak sağlığını olumsuz yönde etkileyen protozoalar ise orta ya da şiddetli enfestasyonlardan sorumlu tutulmaktadır. Kalabalık ve yoğun yetiştiriciliğin yapıldığı kümeslerde koksidiyoz gibi kısa ve direkt yaşam siklusuna sahip hastalıkların ortaya çıkışında artış gözlenmektedir. Koksidiyoza neden olan Eimeira türleri intestinal kanalda çoğalarak doku hasarına neden olmakta, bunun sonucunda da besin maddelerinin sindirim ve emiliminde azalma, canlı ağırlık kayıpları ve mortalite oranında artış şekillenmektedir. Lezyonların şiddeti; konakçı canlı tarafından alınan oositlerin açılma derecelerine bağlıdır ${ }^{33}$. Subklinik koksidiyosis, Clostridium perfringens'in çoğalmasına firsat vererek nekrotik enteritisin gelişimine yol açmaktadır. Ayrıca birçok viral enfeksiyonda bağırsak sağlığı negatif yönde etkilenmektedir. Bunlar; rotaviruslar, coronaviruslar, enteroviruslar, adenoviruslar, astroviruslar ve reoviruslardır.

\section{Toksinler}

Yem kaynaklı toksinler bağırsak sağlığının bozulmasına yol açabilmektedir. Mikotoksinler ve biyojenik aminler yem kaynaklı toksinlerin en yaygin olanlarıdır ${ }^{7}$. Kanatlı yemlerinin mikotoksinler ile bulaşık olması, bağırsak sağl1ğını bozmak ve performans düşüklügüne yol açmak suretiyle ekonomik kayıplara neden olmaktadır ${ }^{25}$. T-2 toksini gibi mikotoksinler, sindirim sistemi mukozasinda yaralanmalara, villuslarda epitel hücre kayıplarına yol açarak bağırsak villuslarının kısalmasına, proventrikulus ve taşlıkta ise nekrozlara neden olmaktadır ${ }^{13}$. Hayvansal protein kaynaklarında mevcut olan histamin, kadaverin, püresin, spermin ve spermidin gibi biyojenik aminlerin yol açtığı malabsorbsiyon sendromu ise; proventrikulusun genişlemesine ve yemden yararlanmanın düşmesine yol açmaktadır ${ }^{26}$.

Sonuç olarak; kanatlı hayvanlarda bağırsak sağlığı optimal sindirim ve emilim için hayati önem taşımaktadır. Bağırsak sağlığı üzerindeki olumsuz etkiler; başlıca gastro-intestinal kanaldaki mikrobiyel dengesizliklerden kaynaklanmaktadır. NYOP'ler, yem ham maddelerinin fiziksel yapısı ve toksinler gibi birçok faktör bağırsak sağlığı üzerinde etkili olarak ticari kanatlı işletmelerinin karlılığını etkilemektedir. Diğer taraftan; prebiyotik, probiyotik ve enzimler gibi yem katkı maddeleri kanatlı hayvanlarda bağırsak mikroflorasını ve performansı iyileştirmektedir. $\mathrm{Bu}$ nedenle, rasyonların formülasyonu sirasinda gastro-intestinal mikrolflora üzerinde etkili olan faktörler göz önünde tutulmalıdir.

\section{Kaynaklar}

1. Apajalahti J. H. A., Kettunen A., Graham H., 2004. Characteristics of the gastro-intestinal microbial communities with special reference to the chicken. World’s Poult. Sci., J. 60,223-232.

2. Apajalahti J. H.A., Kettunen H., Kettunen A., Holben W. E., Nurminen P. H., Rautonen N., Mutanen M., 2002. Culture-independent microbial community analysis reveals that inulin in the diet primarily affects previously unknown bacteria in the mouse cecum. Appl. Environ. Microbiol., 68, 4986-4995.

3. Bigot K., Mignon-Grasteau S., Picard M., Tesseraud S., 2003. Effects of delayed feed intake on body, intestine, and muscle development in neonate broilers. Poult. Sci., 82, 781-788.

4. Branton S. L., Lott B. D., Deaton J. W., Maslin W. R., Austin F. W., Pote L. M., Keirs R. W., Latour M. A., Day E. J., 1997. The effect of added complex carbohydrates oradded dietary fiber on necrotic enteritis lesions in broiler chickens. Poult. Sci., 76,24-28.

5. Choct M., Annison G., 1992. Soluble wheat pentosans exhibit different anti-nutritive ac- 
tivities in intact and cecectomized broiler chickens. J. Nutr., 122,2457-2465

6. Craven S. E., Cox N. A., Bailey J. S., Cosby D. E., 2003. Incidence and tracking of Clostridium perfringens through an integrated broiler chicken operation. Avian Dis., 47,707-711.

7. Dekich M. A., 1998. Broiler industry strategies for control of respiratory and enteric diseases. Poult. Sci., 77,1176-1180.

8. Engberg R. M., Hedemann M. S., Steenfeldt S., Jensen B. B., 2004. Influence of whole wheat and xylanase on broiler performance and microbial composition and activity in the digestive tract. Poult. Sci., 83, 925-938.

9. Foye O. T., Ferket P. R., Uni Z., 2007. The effects of in ovo feeding arginine, $\beta$-hydroxy- $\beta$ methyl-butyrate, and protein on jejunal digestive and absorptive activity in embryonic and neonatal turkey poults. Poult. Sci., 86,2343-2349.

10. Gabriel I., Lessire M., Mallet S., Guillot J. F., 2006. Microflora of the digestive tract: Critical factors and consequences for poultry. World's Poult. Sci., J. 62,499-511.

11. Geyra A., Uni Z., Sklan D., 2001. Enterocyte Dynamics and mucosal development in the posthatch chick. Poult. Sci., 80,776-782.

12. Hoct M., Annison G., 1992. Anti-nutritive effect of wheat pentosans in broiler chickens: Roles of viscosity and gut microflora. Br. Poult. Sci., 33,821-834.

13. Hoerr F. J., Carlton W. W., Yagen B., 1981. Mycotoxicosis caused by a single dose of T-2 toxin or diacetoxyscirpenol in broiler chickens. Vet. Pathol., 18,652-664.

14. Iji P. A., 1999. The impact of cereal non-starch polysaccharides on intestinal development and function in broiler chickens. World's Poult. Sci., J. 55, 375-387.

15. Jeurissen S. H., Lewis F., Van der Klis J. D., Mroz Z., Rebel J. M., Ter Huurne A.A., 2002. Parameters and techniquesto determine intestinal health of poultry as constitutedby immunity, integrity, and functionality. Curr.Issues Intest. Microbiol., 3,1-14.

16. Korver D. R., 2006. Overview of the immune dynamics of the digestive system. J. Appl. Poult. Res., 15,123-135.

17. Leeson S., Caston L., Kiaei M. M., Jones R., 2000. Commercial enzymes and their influence on broilers fed wheat or barley. J. Appl. Poult. Res., 9,242-251.

18. Lu J., Idris U., Harmon B., Hofacre C., Maurer J. J., Lee M. D., 2003. Diversity and succession of the intestinalbacterial community of the maturing broiler chicken.Appl. Environ. Microbiol., 69,6816-6824.

19. Noy Y., Geyra A., Sklan D., 2001. The effect of early feeding on growth and small intestinal de- velopment in the posthatch poult. Poult. Sci., 80,912-919.

20. Noy Y., Sklan D., 1998. Yolk utilization in the newly hatched poult. Br. Poult. Sci., 39, 446-451.

21. Nurmi E., Rantala M., 1973. New aspects of Salmonella infection in broiler production. Nature, 241, 210-211.

22. Plavnik I., Macovsky B., Sklan D., 2002. Effect of Feeding whole wheat on performance of broiler chickens. Anim. Feed Sci. Technol., 96, 229236.

23. Potturi P. V., Patterson J. A., Applegate T. J., 2005. Effects of delayed placement on intestinal characteristics in turkey poults. Poult. Sci., 84, 816-824.

24. Richards J. D., Gong J., De Lange C. F. M., 2005. The gastrointestinal microbiota and its role in monogastric nutrition and health with an emphasis on pigs: Current understanding, possible modulations, and new Technologies for ecological studies. Can. J. Anim. Sci., 85,421-435.

25. Sklan D., Shelly M., Makovsky B., Geyra A., Klipper E., Friedman A.,2003. The effect of chronic feeding of diacetoxyscirpenol and T-2 toxin on performance, health, small intestinal physiology and antibody production in turkey poults. Br. Poult. Sci., 44,46-52.

26. Stuart B. P., Cole R. J., Waller E. R., Vesonder R. E., 1986. Proventricular hyperplasia (malabsorption syndrome) in broiler chickens. J. Environ. Pathol. Toxicol. Oncol., 6, 369-385.

27. Svihus B., Juvik E., Hetland H., Krogdahl A., 2004. Causes for improvement in nutritive value of broiler chicken diets with whole wheat instead of ground wheat. Br. Poult. Sci., 45,55-60.

28. Tako E., Ferket P. R., Uni Z., 2004. Effects of in ovo feeding of carbohydrates and beta-hydroxybeta-methylbutyrate on the development of chicken intestine. Poult. Sci., 83,2023-2028.

29. Uni Z., 1998. Impact of early nutrition on poultry: Review of presentations. J. Appl. Poult. Res., 7,452-455.

30. Uni Z., Ganot S., Sklan D., 1998. Posthatch development of mucosal function in the broiler small intestine. Poult. Sci., 77, 75-82.

31. Uni Z., Noy Y., Sklan D., 1999. Posthatch development of small intestinal function in the poult. Poult. Sci., 78,215-222.

32. Uni Z., Tako E., Gal-Garber O., Sklan D., 2003. Morphological, molecular, and functional changes in the chicken small intestine of the late-term embryo. Poult. Sci., 82, 1747-1754.

33. Williams R. B., 2005. Intercurrent coccidiosis and necrotic enteritis of chickens: Rational, integrated disease management by maintenance of gut integrity. Avian Pathol., 34, 159-180. 
